\title{
Modeling and Simulation of Cigarette Weight Control System
}

\author{
Yuan Zhanjun* \\ Department of Electronic Engineering, Shaanxi Institute of International Trade \& Commerce, Xianyang, Shaanxi, \\ 712046, P.R. China
}

\begin{abstract}
Aiming at the nonlinearity, long time-delay and other such influencing factors for cigarette weight control, this paper analyzes the problems existing in the traditional PID control algorithm. And puts forward designing methods for cigarette's weight fuzzy control system based on TMS320F2812 DSP. The working principle and overall structure of cigarette weight control system has been analyzed, and the mathematical model of each system component part has been studied. Based this work, a system simulation model has been established. At the same time, the design of the fuzzy controller has been completed through analysis and induction of the practical operating experience and expert knowledge. Through simulation researches, the results show that the cigarette weight fuzzy control system than the PID control system, has faster dynamic response speed, shorter adjusting time and smaller system overshoot. In system design, fuzzy control method can effectively ensure the stability and rapidity of cigarette weight control. Furthermore, the results prove that the fuzzy controller design method is correct and effective.
\end{abstract}

Keywords: Cigarette making machine, fuzzy control, modeling and simulation, weight control system.

\section{INTRODUCTION}

The cigarette weight control system is an important part of the cigarette making machine, its main function is to control the actuating mechanism for adjusting cigarette's weight, based on detection and data processing of on-line cigarette weight, its control effect directly affects the cigarette quality and raw material consumption. At present the cigarette weight control often adopts the PID algorithm, but it is very difficult for this algorithm to achieve good controlling effect regarding cigarette weight control. There are two main reasons: (1) the cigarette weight control system is a nonlinear, time-varying and complex system. When the external conditions are change, the PID parameter needs to be readjusted according to the system parameters, otherwise it would lead to a decline in system's control accuracy. (2) When the weight deviation is large, there will be an integral saturation phenomenon, causing the big system to overshoot and requiring longer regulating time [1].

Aimed at these above problems, this paper adopts TMS320F2812 DSP as the microprocessor, well solves the shortcomings of PID control system by using the fuzzy control algorithm, and completes the cigarette weight control system design [2]. Based on analyzing the mathematical model of each system component part, the system simulation model has been established. At the same time, this paper also completes the design of fuzzy controller, and carries out comparative study for system simulation.

\section{SYSTEM HARDWARE STRUCTURE AND WORK- ING PRINCIPLE}

The hardware structure block diagram of the cigarette weight control system is shown in Fig. (1). This system mainly includes TMS320F2812 DSP, microwave weight detection unit, shaft encoder, execution unit, power supply circuit, clock circuit, protection circuit, CAN bus interface circuit and man-machine interface [3].

The system working principle is as follows: Firstly, the density of the cigarette rod traveling through the resonant cavity is detected by microwave weight detection unit, and the digital quantity of the cigarette density is obtained through ADC module conversion in TMS320F2812 [4]. According to the sync pulse and incremental pulse captured by CAP1 pin and CAP3 pin respectively, continuous cigarette rod weight is divided into single cigarette weight, and then average cigarette weight and single cigarette weight are calculated. Secondly, according to the deviation of average cigarette weight and the setting cigarette weight, the system controls cleaver motor to adjust the cleaver plate height, changes tobacco cutting to complete cigarette weight control [5]. At the same time, the faulty cigarettes are removed through relevant rejection valves. Finally, data communication between DSP and industrial computer is realized by the use of CAN bus [6].

\section{ESTABLISHMENT OF THE SYSTEM MODEL}

Fig. (2) Shows the structural schematic diagram for the cigarette weight control system, mainly including controller, execute component, mechanical transmission link and cigarette weight detection link. 


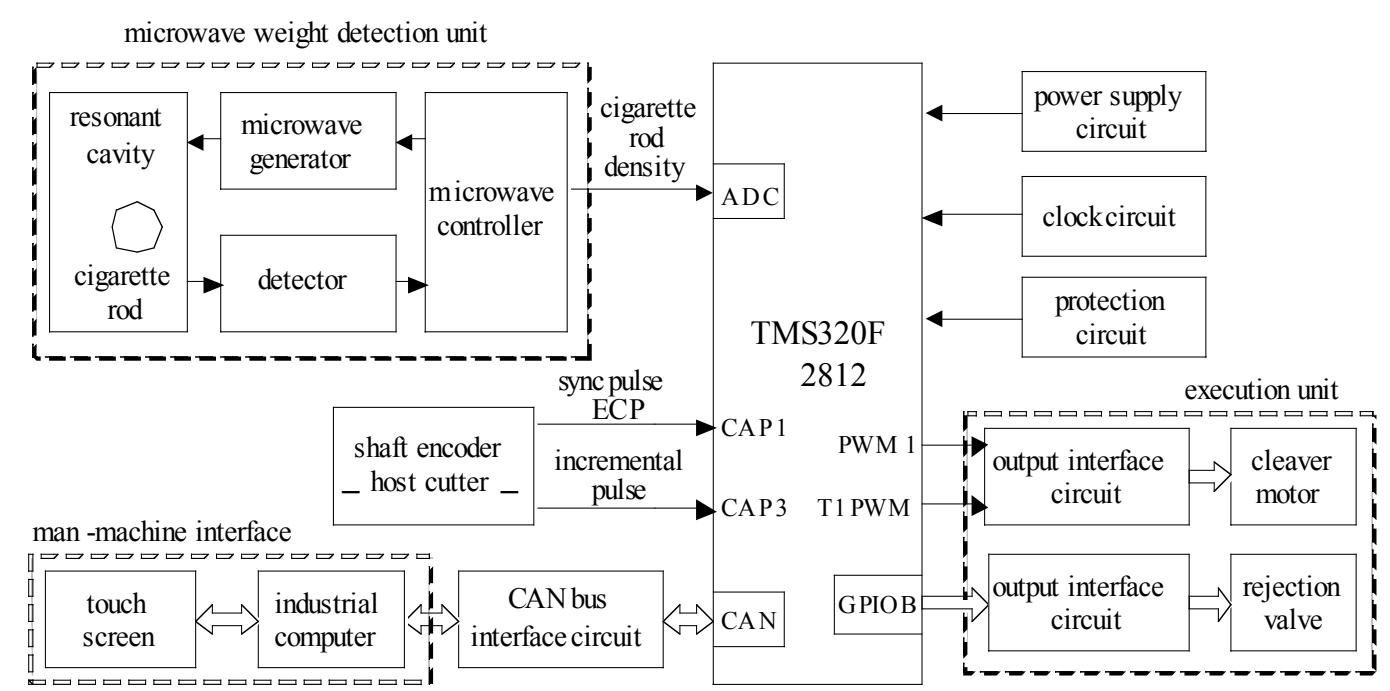

Fig. (1). Hardware structure block diagram of the cigarette weight control system.

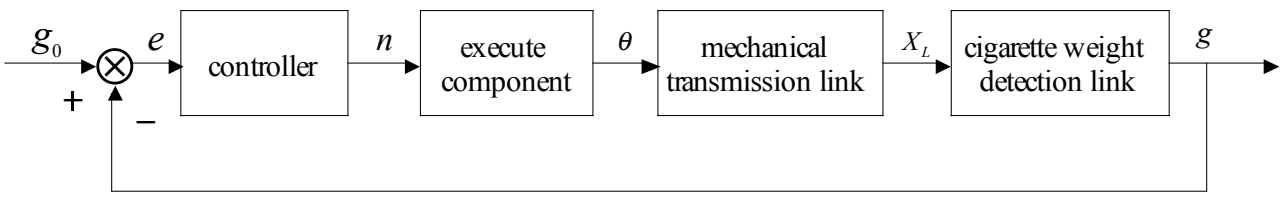

Fig. (2). Structural schematic diagram of the cigarette weight control system.

This system is a complex control system, including electrical and mechanical parts. The mathematical model for each component must be analyzed first in order to establish the whole system's mathematical model, of which is as follows:

\subsection{Execute Component Model}

The cleaver motor as the system executes the component it adopts the three-phase stepper motor. The input voltage pulse number of stepper motor can be accurately converted into an angular displacement $\theta$ of the output shaft, the mathematical model of stepper motor can be expressed as:

$\theta=\theta_{N} \bullet N^{\prime}=360^{\circ} \bullet n$

where $\theta_{N}$ the step angle of stepper is motor, $N^{\prime}$ is the input pulse number, and $n$ is the rotation number of stepper motor [7].

\subsection{Mechanical Transmission Link Model}

The mechanical transmission device diagram for the cigarette weight control system is shown in Fig. (3). in this diagram the input is the angular displacement $\theta$ of stepper motor, and the output is the displacement $X_{L}$ of work table. $J_{1}, J_{2}$ represent the rotational inertias of stepper motor reel and screw shaft, respectively. $K_{1}, K_{2}$ represent the torsional stiffness of stepper motor reel and screw shaft, respectively, and $i$ is the gear reduction ratio.

After considering the rigidity and damping of the transmission chain, the input-output differential equations of mechanical transmission link can be expressed as:
$J_{L} \frac{d^{2} X_{L}}{d t^{2}}+f_{L} \frac{d X_{L}}{d t}+K_{L} X_{L}=\frac{S_{0}}{2 \pi i} K_{L} \theta$

where $J_{L}$ is the total rotational inertia converted onto the screw shaft, $f_{L}$ is the viscous damping coefficient converted onto the screw shaft, $K_{L}$ is the total equivalent torsional stiffness converted onto the screw shaft, and $S_{0}$ is the screw lead [8].

According to the above differential equations, the transfer function of mechanical transmission link can be expressed as:

$G_{L}(S)=\frac{X_{L}(S)}{\theta(S)}=\frac{\frac{S_{0}}{2 \pi i} K_{L}}{J_{L} S^{2}+f_{L} S+K_{L}}=\frac{S_{0}}{2 \pi i} \bullet \frac{\omega_{0}^{2}}{S^{2}+2 \xi \omega_{0} S+\omega_{0}^{2}}$

where $\omega_{0}=\sqrt{K_{L} / J_{L}}, \xi=f_{L} /\left(2 \sqrt{J_{L} K_{L}}\right)$.

\subsection{Cigarette Weight Detection Link Model}

Because the displacement $X_{L}$ of the work table and cleaver is proportional to the cigarette weight $g$, the transfer function of cigarette weight detection link can be written as:

$G_{g}(S)=\frac{g(S)}{X_{L}(S)}=k_{g}$

\subsection{Transfer Function of the Controlled Object}

The execute component, mechanical transmission link and cigarette weight detection linked together are referred as 


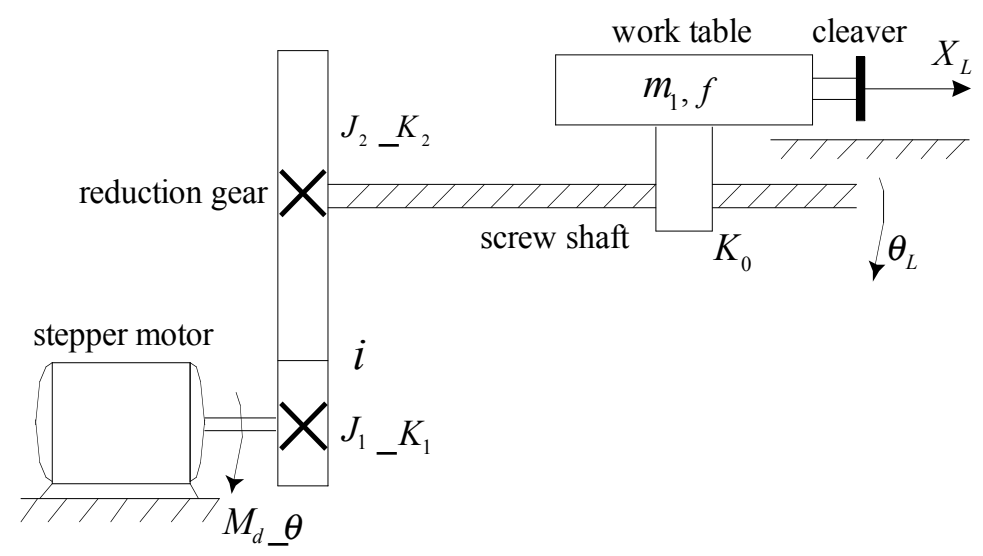

Fig. (3). Mechanical transmission device diagram of the system.

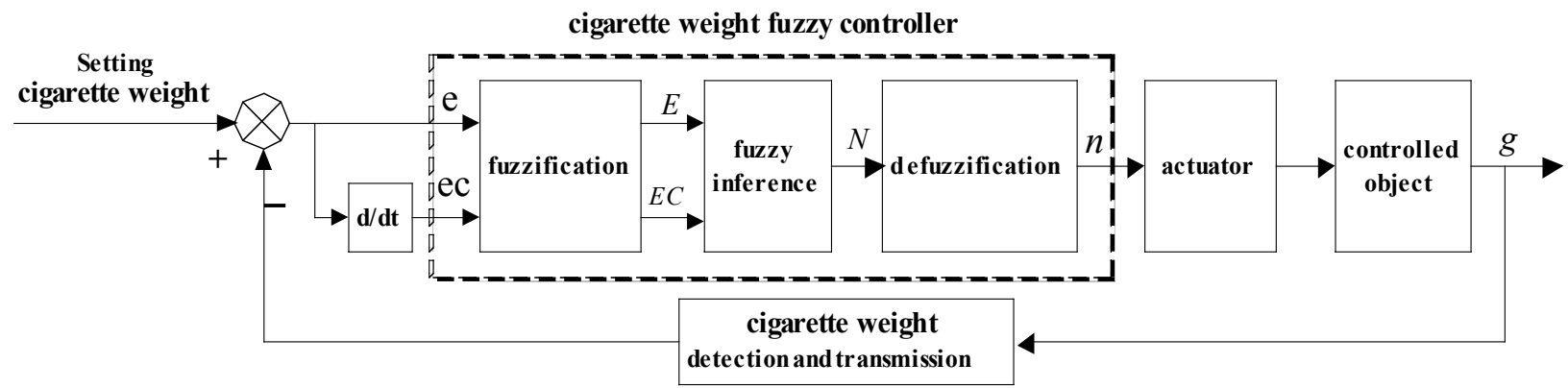

Fig. (4). the structure diagram of cigarette weight fuzzy controller.

the controlled object. By the above analysis, the transfer function $G(S)$ of the controlled object can be written as:

$$
\begin{aligned}
& G(S)=\frac{g(S)}{n(S)}=\frac{g(S)}{X_{L}(S)} \bullet \frac{X_{L}(S)}{\theta(S)} \bullet \frac{\theta(S)}{n(S)}=k_{g} \bullet \frac{S_{0}}{2 \pi i} \bullet \\
& \frac{\omega_{0}{ }^{2}}{S^{2}+2 \xi \omega_{0} S+\omega_{0}{ }^{2}} \bullet 2 \pi
\end{aligned}
$$

In practical research, system execute component adopts stepper motor 70BF003, which works in three-phase six pats. The main electrical parameters of stepper motor are as follows: $\alpha=1.5^{\circ}, \quad J_{m}=0.257 \mathrm{~kg} \bullet \mathrm{cm}^{2}$, the maximum static torque is $0.784 \mathrm{~N} \bullet \mathrm{m}$. The parameters of mechanical transmission link are: rolling screw diameter $d=20 \mathrm{~mm}$, screw lead $S_{0}=3 \mathrm{~mm}$, screw active length $l=160 \mathrm{~mm}$, the minimum tension and compression length of screw $l_{\text {min }}=40 \mathrm{~mm}$, the maximum tension and compression length of screw $l_{\max }=140 \mathrm{~mm}$, the quality of work table and cleaver frame $m_{1}=2 \mathrm{~kg}$, the friction coefficient of the guide rail $f_{L}=0.2, \rho=7.8 \times 10^{3} \mathrm{~kg} / \mathrm{m}^{3}$, the shear modulus of screw $G=8.1 \times 10^{10} \mathrm{~N} / \mathrm{m}^{2}$, the number of gear teeth $z_{1}=20$, $z_{2}=100, i=5$, modulus $m_{0}=2 \mathrm{~mm}$, tooth width $b=20 \mathrm{~mm}$.

According to the above conditions, the actual transfer function of the controlled object can be obtained by calculating:

$$
\begin{aligned}
& G(S)=\frac{g(S)}{n(S)}=k_{g} \bullet \frac{S_{0}}{2 \pi i} \cdot \frac{\omega_{0}^{2}}{S^{2}+2 \xi \omega_{0} S+\omega_{0}^{2}} \cdot 2 \pi \\
& =\frac{27303}{S^{2}+7.63 S+477^{2}}
\end{aligned}
$$

\section{DESIGN OF CIGARETTE WEIGHT FUZZY CON- TROLLER}

\subsection{Fuzzy Controller Structure}

Two-dimensional fuzzy controller can well reflect the nonlinear PD control rule, as it has good dynamic control performance. Furthermore, its structure is not very complex, and its control algorithm is relatively easy to implement [9]. According to the nonlinear and time-varying characteristics of cigarette weight change, the cigarette weight control system uses a two-dimensional fuzzy controller, whose structure is shown in Fig. (4).

\subsection{Fuzzy Language Variables and Membership Func- tions}

The input language variables of cigarette weight fuzzy controller are cigarette weight error $e$ and cigarette weight error variation $e c$. The output language variable of fuzzy controller is the rotation number of the stepper motor $n$. The cigarette weight error and weight error variation can be respectively expressed as:

$$
\begin{aligned}
& e(k)=g(k)-g_{0} \\
& e c(k)=e(k)-e(k-1)
\end{aligned}
$$


Table 1. The Assignment Table of Fuzzy Language Variable $E$.

\begin{tabular}{|c|c|c|c|c|c|c|c|c|c|c|c|}
\hline$\underset{\substack{\text { language } \\
\text { value }}}{\mu(x)} E$ & -5 & -4 & -3 & -2 & -1 & 0 & +1 & +2 & +3 & +4 & +5 \\
\hline $\mathrm{PB}$ & 0 & 0 & 0 & 0 & 0 & 0 & 0 & 0 & 0 & 0.5 & 1.0 \\
\hline PM & 0 & 0 & 0 & 0 & 0 & 0 & 0 & 0.6 & 0.6 & 0 & 0 \\
\hline PS & 0 & 0 & 0 & 0 & 0 & 0 & 0.8 & 0.3 & 0 & 0 & 0 \\
\hline $\mathrm{ZO}$ & 0 & 0 & 0 & 0 & 0 & 1.0 & 0 & 0 & 0 & 0 & 0 \\
\hline NS & 0 & 0 & 0 & 0.3 & 0.8 & 0 & 0 & 0 & 0 & 0 & 0 \\
\hline NM & 0 & 0 & 0.65 & 0.65 & 0 & 0 & 0 & 0 & 0 & 0 & 0 \\
\hline NB & 1.0 & 0.5 & 0 & 0 & 0 & 0 & 0 & 0 & 0 & 0 & 0 \\
\hline
\end{tabular}

Table 2. The Assignment Table of Fuzzy Language Variable $E C$.

\begin{tabular}{|c|c|c|c|c|c|c|c|c|c|c|c|}
\hline $\begin{array}{c}\mu(x) E C \\
\text { language } \\
\text { value }\end{array}$ & -5 & -4 & -3 & -2 & -1 & 0 & +1 & +2 & +3 & +4 & +5 \\
\hline $\mathrm{PB}$ & 0 & 0 & 0 & 0 & 0 & 0 & 0 & 0 & 0 & 0.30 & 1.0 \\
\hline $\mathrm{PM}$ & 0 & 0 & 0 & 0 & 0 & 0 & 0 & 0.15 & 0.8 & 0.6 & 0 \\
\hline $\mathrm{PS}$ & 0 & 0 & 0 & 0 & 0 & 0 & 0.6 & 0.8 & 0.1 & 0 & 0 \\
\hline $\mathrm{ZO}$ & 0 & 0 & 0 & 0 & 0.35 & 1.0 & 0.35 & 0 & 0 & 0 & 0 \\
\hline $\mathrm{NS}$ & 0 & 0 & 0.1 & 0.8 & 0.6 & 0 & 0 & 0 & 0 & 0 & 0 \\
\hline $\mathrm{NM}$ & 0 & 0.6 & 0.8 & 0.15 & 0 & 0 & 0 & 0 & 0 & 0 & 0 \\
\hline $\mathrm{NB}$ & 1.0 & 0.35 & 0 & 0 & 0 & 0 & 0 & 0 & 0 & 0 & 0 \\
\hline
\end{tabular}

where $g(k)$ is the sampling cigarette weight, $g_{0}$ is the setting cigarette weight.

According to the actual working situation and control precision of the cigarette making machine, the basic domain, fuzzy domain, quantitative factor and scale factor of fuzzy language variables can be defined as follows:

For cigarette weight error $e$, its basic domain is $[-0.08$, $0.08] \mathrm{g}$, its fuzzy domain $\mathrm{X}$ is $[-5,-4,-3,-2,-1,0,+1,+2$, $+3,+4,+5]$, its quantitative factor $k_{e}$ is 62.5 . Seven fuzzy subsets $A_{i}(i=1,2, \ldots, 7)$ are defined in the fuzzy domain $\mathrm{X}$, the corresponding language value is $[\mathrm{NB}, \mathrm{NM}, \mathrm{NS}, \mathrm{ZO}, \mathrm{PS}$, PM, PB].

For cigarette weight error variation $e c$, its basic domain is $[-0.02,0.02] \mathrm{g}$, its fuzzy domain $\mathrm{Y}$ is $[-5,-4,-3,-2,-1,0,+1$, $+2,+3,+4,+5]$, its quantitative factor $k_{e c}$ is 250 . Seven fuzzy subsets $B_{j}(j=1,2, \ldots, 7)$ are defined in the fuzzy domain $\mathrm{Y}$, the corresponding language value is $[\mathrm{NB}, \mathrm{NM}, \mathrm{NS}, \mathrm{ZO}$, PS, PM, PB].

As for rotation number of stepper motor $n$, its basic domain is $[-2.5,2.5] \mathrm{r}$, its fuzzy domain $\mathrm{Z}$ is $[-5,-4,-3,-2,-1,0$,
$+1,+2,+3,+4,+5]$, its scale factor $k_{u}$ is 0.5 . Seven fuzzy subsets $C_{k}(k=1,2, \ldots, 7)$ are defined in the fuzzy domain $\mathrm{Z}$, the corresponding language value is [NB, NM, NS, ZO, PS, PM, $\mathrm{PB}]$.

By summarizing the practical experience of the operator, the membership function of the input language variables and the output language, the variables are determined. Then the fuzzy controller respectively sets up the assignment tables for the fuzzy language variables $E, E C$ and $N$, such as shown in Tables 1-3.

\subsection{Design of Fuzzy Control Rule}

The design principle of fuzzy control rules is to ensure that the system output response has the best dynamic and static characteristics. When the cigarette weight error is large, the output control quantity is selected in order to eliminate error quickly. On the contrary, when the cigarette weight error is small, output control quantity is selected to ensure the system stability and reduces the system overshoot [10].

Based on the analysis of the actual operation experience and the summary of expert control knowledge, the fuzzy control rules of cigarette weight are shown in Table 4. 
Table 3. The Assignment Table of Fuzzy Language Variable $N$.

\begin{tabular}{|c|c|c|c|c|c|c|c|c|c|c|c|}
\hline $\begin{array}{c}\text { language } \\
\text { value }\end{array}$ & -5 & -4 & -3 & -2 & -1 & 0 & +1 & +2 & +3 & +4 & +5 \\
\hline PB & 0 & 0 & 0 & 0 & 0 & 0 & 0 & 0 & 0 & 0.55 & 1.0 \\
\hline PM & 0 & 0 & 0 & 0 & 0 & 0 & 0 & 0.4 & 0.8 & 0.3 & 0 \\
\hline PS & 0 & 0 & 0 & 0 & 0 & 0 & 1 & 0.5 & 0 & 0 & 0 \\
\hline ZO & 0 & 0 & 0 & 0 & 0 & 1.0 & 0 & 0 & 0 & 0 & 0 \\
\hline NS & 0 & 0 & 0 & 0.5 & 1.0 & 0 & 0 & 0 & 0 & 0 & 0 \\
\hline NM & 0 & 0.3 & 0.8 & 0.4 & 0 & 0 & 0 & 0 & 0 & 0 & 0 \\
\hline NB & 1.0 & 0.55 & 0 & 0 & 0 & 0 & 0 & 0 & 0 & 0 & 0 \\
\hline
\end{tabular}

Table 4. The Fuzzy Control Rules of Cigarette Weight.

\begin{tabular}{|c|c|c|c|c|c|c|c|}
\hline$E C$ & PB & PM & PS & ZO & NS & NM & NB \\
\hline PB & NB & NB & NM & NM & NS & ZO & ZO \\
\hline PM & NB & NM & NM & NM & NS & ZO & PS \\
\hline PS & NB & NM & NS & NS & ZO & PS & PS \\
\hline ZO & NM & NM & NS & ZO & PS & PM & PM \\
\hline NS & NS & NS & ZO & PS & PS & PM & PB \\
\hline NM & NS & ZO & PS & PM & PM & PM & PB \\
\hline NB & ZO & ZO & PS & PM & PM & PB & PB \\
\hline
\end{tabular}

\subsection{Realization of Fuzzy Control Algorithm}

The realization method of fuzzy control algorithm directly affects the performance of fuzzy controller. In order to improve the real-time performance of cigarette weight control, the look-up table method is used to achieve fuzzy control algorithm [11].

The fuzzy control rules shown in Table $\mathbf{4}$ can be written as follows:

IF $E=A_{i} \quad A N D \quad E C=B_{j} \quad T H E N \quad N=C_{i j}$

$(i=1,2, \ldots, 7 ; j=1,2, \ldots, 7)$

where $A_{i}$ is a fuzzy subset of the cigarette weight error $E$, $B_{j}$ are fuzzy subsets of the cigarette weight error variation $E C, C_{i j}$ is fuzzy subset of the output control quantity $N$. The fuzzy control rules table contains 49 fuzzy relations, which can be expressed separately as follows:

$R_{1}=\left[(P B)_{E} \times(P B)_{E C}\right]^{T} \times(N B)_{N}$

$$
R_{2}=\left[(P M)_{E} \times(P B)_{E C}\right]^{T} \times(N B)_{N}
$$

$R_{48}=\left[(N M)_{E} \times(N B)_{E C}\right]^{T} \times(P B)_{N}$

$R_{49}=\left[(N B)_{E} \times(N B)_{E C}\right]^{T} \times(P B)_{N}$

Through the union operation of these fuzzy relations, the overall fuzzy relations of the system control rules can be described as follows:

$$
R=\bigcup_{l=1}^{49} R_{l}=\bigcup_{\forall i, j} A_{i} \times B_{j} \times C_{i j} \quad(i=1,2, \ldots, 7 ; j=1,2, \ldots, 7)
$$

The membership function $R$ can be written as follows:

$$
i=7, j=7
$$

$\mu_{R(x, y, z)}=\underset{i=1, j=1}{\vee} \mu_{A_{i}(x)} \wedge \mu_{B_{j}(y)} \wedge \mu_{C_{i j}(z)}$

$(x \in X, y \in Y, z \in Z)$ 


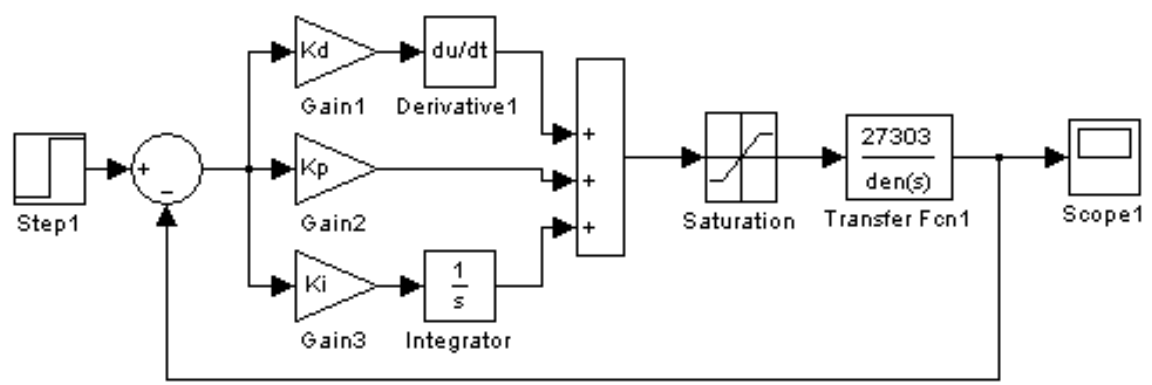

Fig. (5). System simulation diagram under the PID control.

\section{Table 5. The Fuzzy Control Query Table.}

\begin{tabular}{|c|c|c|c|c|c|c|c|c|c|c|c|}
\hline$E C N$ & -5 & -4 & -3 & -2 & -1 & 0 & +1 & +2 & +3 & +4 & +5 \\
\hline-5 & 5 & 5 & 5 & 4 & 4 & 3 & 2 & 1 & 1 & 0 & 0 \\
\hline-4 & 5 & 5 & 4 & 4 & 4 & 3 & 2 & 0 & 0 & -1 & -1 \\
\hline-3 & 5 & 5 & 3 & 3 & 3 & 3 & 1 & 0 & 0 & -1 & -1 \\
\hline-2 & 5 & 5 & 3 & 2 & 2 & 2 & 1 & -1 & -1 & -1 & -1 \\
\hline-1 & 4 & 4 & 3 & 2 & 1 & 1 & 0 & -2 & -2 & -2 & -2 \\
\hline 0 & 3 & 3 & 3 & 2 & 1 & 0 & -1 & -2 & -3 & -3 & -3 \\
\hline+1 & 2 & 2 & 2 & 2 & 0 & -1 & -1 & -2 & -3 & -4 & -4 \\
\hline+2 & 1 & 1 & 1 & 1 & -1 & -2 & -2 & -2 & -3 & -5 & -5 \\
\hline+3 & 1 & 1 & 0 & 0 & -1 & -3 & -3 & -3 & -3 & -5 & -5 \\
\hline+4 & 1 & 1 & 0 & 0 & -2 & -3 & -3 & -4 & -4 & -5 & -5 \\
\hline+5 & 0 & 0 & -1 & -1 & -2 & -3 & -4 & -4 & -5 & -5 & -5 \\
\hline
\end{tabular}

when the cigarette weight error and error variation select the fuzzy subset $A_{i}$ and the fuzzy subset $B_{j}$ respectively, according to fuzzy inference synthesis rules the output control quantity $N_{i j}$ can be written as follows:

$N_{i j}=\left(A_{i} \times B_{j}\right) \circ R$

Aiming at all combinations of the elements in fuzzy domain $\mathrm{X}$ and $\mathrm{Y}$, the corresponding fuzzy sets of the output control quantity $\mathrm{N}$ are obtained in the light of fuzzy inference synthesis rules. At the same time, considering the high real-time requirements of the cigarette weight control system, the fuzzy controller uses the maximum membership degree method for defuzzification, and calculates the output control quantity in fuzzy domain $\mathrm{Z}$. Based on the off-line calculation, the cigarette weight control system establishes the fuzzy control query table as shown in Table $\mathbf{5}$.

In practical work, the system first detects the density of the cigarette rod and processes the sampled data, then respectively quantifies the cigarette weight error and error variation in fuzzy domain $\mathrm{X}$ and $\mathrm{Y}$ by calling the fuzzy control algorithm. Finally, according to the quantitative results, the system acquires the output control quantity $\mathrm{N}$ by querying fuzzy control query table, and calculates the accurate value of output control quantity $n$, namely rotation number of the stepper motor, and realizes system real-time control.

\section{SIMULATION RESULTS}

In order to compare the performance of PID controller and fuzzy controller in the cigarette weight control, and provide the theoretical basis for the design of the actual controller, the comparative study of system simulation is carried out in MATLAB environment.

According to the transfer function $G(S)$ of the controlled object and the different controllers chosen, the simulation diagrams of cigarette weight control system are established under the PID control and fuzzy control, respectively [12]. Fig. (5) Is the system simulation diagram under the PID control. Fig. (6) is the system simulation diagram under the fuzzy control.

In the system simulation, cigarette target weight is set to $0.9 \mathrm{~g}$. When the system inputs the step signal whose amplitude is 0.9 , the step response curves of cigarette weight PID control system and fuzzy control system are shown in Fig. (7) and Fig. (8), respectively.

From Fig. (7), we can see that the step response parameters of the PID control system are as follows: The overshoot of system is $11 \%$, the rise time $t_{r}$ is 0.6 seconds, the adjusting time $t_{s}$ is 2.4 seconds, and the steady-state error of system is zero.

From Fig. (8), we can see that the step response parameters of the fuzzy control system are as follows: The over- 


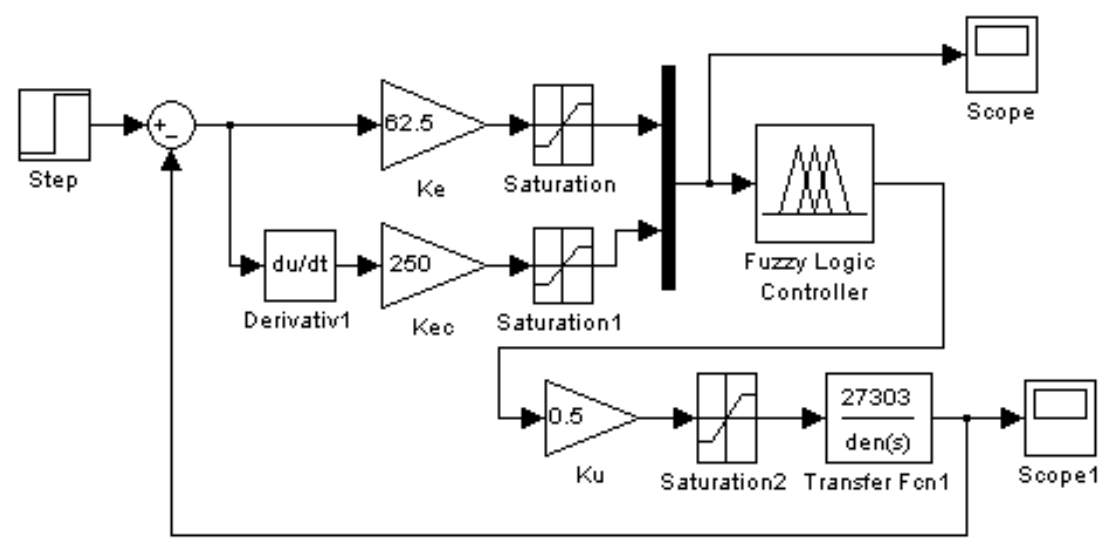

Fig. (6). System simulation diagram under the fuzzy control.

shoot of the system is $2.3 \%$, the rise time $t_{r}$ is 0.2 seconds, the adjusting time $t_{s}$ is 1.2 seconds, and the steady-state error of system is zero.

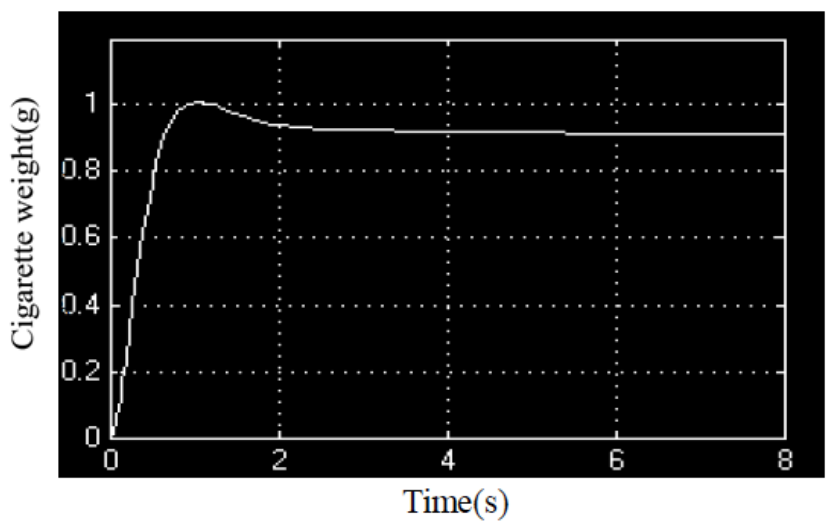

Fig. (7). Step response curve of cigarette weight PID control system.

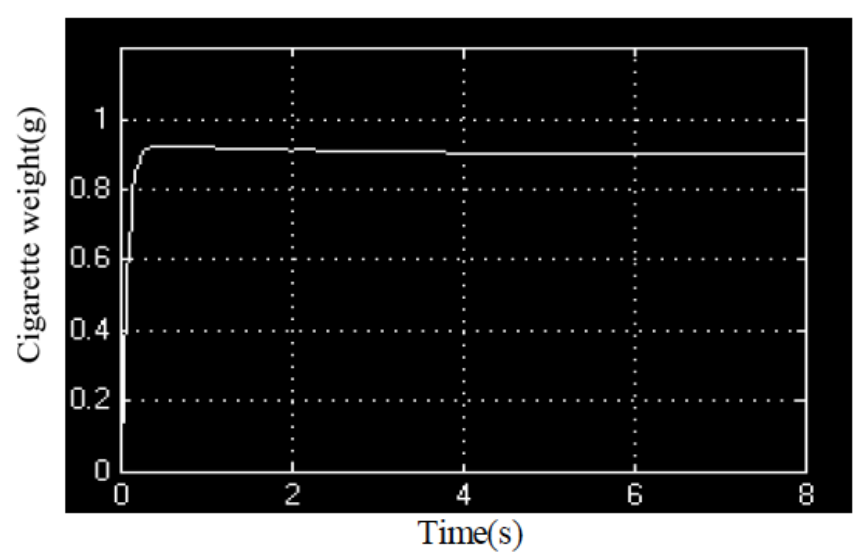

Fig. (8). Step response curve of cigarette weight fuzzy control system.

The simulation results show that the PID control system has a longer transition time, larger system overshoot and poor control quality, also it is to be noted that the PID control system of cigarette weight easily appears in the cigarette weight fluctuations, unstable quality and high reject ratio in the actual production. On the contrary, the fuzzy control system of cigarette weight has the advantage of fast response, short adjusting time and small overshoot. By contrast, we can find that fuzzy control method can effectively ensure the stability and rapidity of cigarette weight control. Furthermore, the results also prove that the new fuzzy control algorithm of cigarette weight is effective and feasible.

\section{CONCLUSION}

This paper adopts TMS320F2812 as core, completes the cigarette weight control system design based on the fuzzy control algorithm. The mathematical model of each system component part is analyzed, based on the above works, the system simulation model is established. This paper mainly introduces the design methods and steps of fuzzy controller in detail. Through simulation experiments, the results show that the cigarette weight fuzzy control system in comparison with the PID control system has a faster dynamic response speed, shorter adjusting time and smaller system overshoot. At the same time, in the study of the cigarette weight control system, the system modeling method and fuzzy controller design method have been found to have certain universality and it can be applied to other nonlinear complex system design as well.

\section{CONFLICT OF INTEREST}

The authors confirm that this article content has no conflict of interest.

\section{ACKNOWLEDGEMENTS}

This work is supported by the Science and Technology Research and Development Project of Shaanxi Province, China (No.2013k07-44).

\section{REFERENCES}

[1] X. X. Ma, S. R. Dai, and H. Z. Li, "Gyro temperature control system based on fuzzy control," Journal of Chinese Inertial Technology, vol. 12, pp. 68-71, 2012.

[2] Y. S. Kung and M. H. Tsai, "FPGA-based speed control IC for PMSM drive with adaptive fuzzy control," IEEE Transaction on Power Electronics, vol. 22, pp. 2476-2486, 2007.

[3] X. M. Ma and Q. T. Zhang, "Real-time detection \& control of cigarette weight system based on TMS320F2812," Microelectronics \& computer, vol. 27, pp. 86-89, 2010. 
[4] Y. S. Kung, "Design and implementation of a high-performance PMLSM drives using DSP chip," IEEE Transactions on Industrial Electronics, vol. 55, pp. 1341-1351, 2008.

[5] L. Sun, "Design of weight control system in ZJ19A cigarette maker based on LF2407A," Computer Measurement \& Control, vol. 17, pp. 316-318, 2009.

[6] H. B. Li, X. D. Wang, and L. Xue, "Can bus research and fulfill based on DSP," Journal of Harbin University of Science and Technology, vol. 10, pp. 72-75, 2005.

[7] J. Han, Y. Y. Liu, and L. Xia, "Research on simulation system of virtual three-phase stepping motor," Computer Aided Drafting, Design and Manufacturing, vol. 22, pp. 74-77, 2012.
[8] Q. S. Zhang, K. C. Wang, and F. Y. Li, "Research on transfer function of electric actuator," Process automation instrumentation, vol. 28, pp. 67-69, 2007.

[9] Z. L. Zhao, "Fuzzy PID controller design of cigarette weight control system," Journal of Shenyang Institute of Aeronautical Engineering, vol. 27, pp. 36-38, 2010.

[10] H. C. Guo, T. Y. Qiu, and J. C. Jiang, "Design of fuzzy controller for direct drive wind turbines," Journal of Shanghai Jiaotong University (Science), vol. 17, pp. 209-214, 2012.

[11] J. Zhu, Fuzzy Control Theory and System Principle, Beijing, 2005, pp. 228-238.

[12] Q. M. Cheng, "A study on integrated controllers with fuzzy control and PID control and their simulations," Journal of Applied Sciences, vol. 20, pp. 432-434, 2002.

(C) Yuan Zhanjun; Licensee Bentham Open.

This is an open access article licensed under the terms of the Creative Commons Attribution Non-Commercial License (http://creativecommons.org/licenses/by-nc/3.0/) which permits unrestricted, non-commercial use, distribution and reproduction in any medium, provided the work is properly cited. 